\title{
Acción Colectiva por la Educación: o assalto à educação chilena
}

\section{Resumo}

Este artigo apresenta os resultados da pesquisa sobre as novas formas de associação burguesa no Chile, expressos na Acción Colectiva por la Educación, organização composta por diversos aparelhos privados de hegemonia educacional. A proposta dirigiu-se à problematização das novas formas de organização burguesa, aparelhos de ação política que incidem sobre as políticas educacionais. Os procedimentos metodológicos adotados para realização deste texto foram: pesquisa documental e bibliográfica e análise de redes sociais. Identificamos que uma fração da burguesia chilena, especialmente as organizações empresariais, configuram novas formas de associações coletivas. Esta elite orgânica busca manter um controle hegemônico nas determinações do capital sobre a educação lastreada nas recomendações de organismos multilaterais.

Palavras-chave: Acción Colectiva por la Educación; aparelho de ação política; elite orgânica; política de educação.

\section{Letícia Fiera}

Secretaria de Estado da Educação de Santa Catarina - SED Florianópolis/SC - Brasil leticia.fiera@gmail.com

\section{Para citar este artigo:}

FIERA, Letícia. Acción Colectiva por la Educación: o assalto à educação chilena. Revista Linhas. Florianópolis, v. 22, n. 49, p. 217-242, maio/ago. 2021. Acción Colectiva por la Educación: o assalto à educação chilena 


\title{
Collective action for education: the assault on Chilean education
}

\begin{abstract}
This article presents the results of the research on the new forms of bourgeois association in Chile, expressed in the Acción Colectiva por la Educación, composed of several private devices of educational hegemony. The work proposal was directed, therefore, to problematize the new forms of bourgeois organization in Chile, apparatus of political action, which affect educational policies. The methodological procedures adopted to carry out the research were: document analysis, bibliographic research and analysis of social networks. We have identified that a fraction of the Chilean bourgeoisie, especially business organizations, seeks to influence educational policies by developing new forms of collective associations. This organic elite seeks to maintain hegemonic control over the determinations of capital under education based on the recommendations of multilateral organizations.
\end{abstract}

Keywords: Acción Colectiva por la Educación; political action apparatus; organic elite; education policy. 
O Chile é conhecido como o laboratório mais eficiente das políticas neoliberais entre os países latino-americanos e o país cujas desigualdades sociais são as mais elevadas, afirmou Carlos Mussi, diretor da Comissão Econômica para a América Latina e o Caribe das Nações Unidas (Cepal)1. Isso é interessante, pois demonstra as contradições entre as classes antagônicas no capitalismo contemporâneo. É sempre uma grande ousadia intelectual observar um país com base numa perspectiva crítica, sem estar presente in lócus, mesmo que os recursos às novas tecnologias ajudem na pesquisa e os pesquisadores presentes neste texto reconheçam que o momento histórico é avassalador no que diz respeito à destruição da educação e do trabalho como direitos universais.

Nas pesquisas empíricas sobre a Rede Latino Americana pela Educação (Reduca) (FIERA, 2019; MARTINS, 2019), me deparei com uma nova forma de organização associativa burguesa no Chile, Acción Colectiva por la Educación, criada em 2017, a qual aglutina alguns aparelhos privados de hegemonia orientados para prestação de serviço, seja na oferta de formação docente, de jovens, educação inclusiva e elaboração de documentos sobre política educacionais, além de serem contemplados pelas parcerias entre o público e o privado no campo da educação. Logo, comecei a me indagar sobre o tipo de relação estabelecido entre eles, quem eram os seus organizadores, e procurei compreender a formação e a permanência das classes dominantes no Chile, assim como as diretrizes propostas para o campo educacional. Tais elementos delineiam o processo de reprodução do sistema sociometabólico do capital (MÉSZÀROS, 2011).

As mudanças ocorridas na educação latino-americana nas últimas décadas têm demonstrado o impacto do atual estágio de acumulação capitalista reforçado pelos acordos internacionais como condição necessária para a subordinação da educação perante os interesses do capital (DALE, 2004, p. 454). Silveira (2012) considera que organismos supranacionais como Banco Mundial (BM), Organizações das Nações Unidas (ONU), Organização para a Cooperação e Desenvolvimento Econômico (OCDE), Banco

\footnotetext{
${ }^{1}$ Notícia publicada pelo jornalista André Duchiade sobre os protestos da classe trabalhadora no Chile, na Revista Época, em outubro de 2019. Disponível em: https://epoca.globo.com/mundo/desigualdade-do-chileelevada-mas-parecida-com-do-resto-do-continente-24036639. Acesso em: 11 mar. 2020.
} 
Interamericano de Desenvolvimento (BID), Fundo Monetário Internacional (FMI), Organização Mundial do Comércio (OMC), Organização Internacional do Trabalho (OIT), bem como entidades de caráter regional, a exemplo da Comissão Econômica para a América Latina e o Caribe (CEPAL), entre outras, manifestam os interesses gerais dos Estados-Nações e da classe dominante no poder por meio das contradições entre capital e trabalho, capital e tecnologia, trabalho e produção, trabalho e educação.

Os encontros internacionais de Jomtien (1990), Nova Deli (1993), Dakar (2000) e Incheon (2015) patrocinados pela Organização das Nações Unidas para a Educação, a Ciência e a Cultura (UNESCO), Fundo das Nações Unidas para a Infância (UNICEF), Programa das Nações Unidas para o Desenvolvimento (PNUD) e Banco Mundial tiveram como objetivo orientar as metas e diretrizes das políticas educacionais em escala global. Constata-se, portanto, uma sinergia entre organismos supranacionais em relação às orientações e recomendações para a efetivação dos interesses da burguesia no continente latino-americano.

No que toca as questões relativas aos acordos internacionais na América Latina e Caribe, foi elaborado o Marco Regional de Ação - Marco de Acción Regional Educación para todos en las Américas - Santo Domingo, República Dominicana (2000), que reforça enfaticamente a participação de organizações da sociedade civil (associações de trabalhadores, sindicatos, negócios, partidos políticos, povos indígenas, jovens, mulheres, organizações comunitárias, sociedades artísticas e culturais, para citar alguns) a tomarem parte nas discussões sobre políticas educacionais. Ademais, os países comprometeram-se a criar marcos regulatórios, institucionais e financeiros a fim de legitimar a participação dessas organizações na preparação, monitoramento e avaliação de políticas educacionais, bem como planos e programas nacionais nessas questões².

\footnotetext{
${ }^{2}$ Evangelista (2012a) demonstra como as políticas educacionais no Governo Lula foram sintetizadas desde o Governo FHC, tais como o crescimento da privatização do ensino superior, inclusive sob a modalidade de concessão de bolsa de estudo e a oferta de formação docente, majoritariamente por escolas particulares e sob a forma de EaD. No que se refere ao discurso ideológico, Evangelista (2012a) constata que a substituição do sintagma ideológico "ação estatal" pela "ação pública" estimulou as parcerias públicoprivadas ao criar o solo no qual cresceriam, no governo Lula, os aparelhos privados de hegemonia, de todos os tipos, arautos dos interesses burgueses. O caso mais expoente é o Movimento Todos pela Educação, criado em 2006, que juntamente com uma malha de entidades empresariais (Fundação Lemann, Instituto Ayrton Senna, Instituto Península, entre outros) e entidades financeiras (Bancos Itaú, Santander, Bradesco etc.) disputam a orientação das políticas educacionais brasileira.
} 
Os efeitos sociopolíticos da configuração da sociedade civil chilena apresentam uma diversidade de possibilidades de arranjos participativos, institucionalizados junto à esfera estatal. Essa pluralidade de participação traz consigo variadas expressões de projetos de ordem ideológica e social presentes na atuação de organizações da sociedade civil. Cabe ressaltar que nos filiamos à concepção que considera a sociedade civil como um conjunto de aparelhos privados produtores e difusores de hegemonia (CASIMIRO, 2018). Assim, trata-se de reconhecer que, sob a perspectiva da totalidade, o traçado da vida social ocorre mediante a necessidade de compreender o real. É com essas considerações que compreender a política educacional chilena do século XXI é um desafio, pois a história está em movimento e as articulações organizativas e diretivas dos interesses do capital se atualizam rapidamente.

A perspectiva teórica gramsciana de Estado Ampliado (VIOLIN, 2006) e da sua articulação em dois planos distintos, sociedade civil e sociedade política, cuja inter-relação é indissociável, possibilita desenvolver uma análise da totalidade social a fim de compreender uma racionalidade própria do atual estágio do capitalismo. Logo, as contribuições são relevantes, uma vez que a concepção de Estado ampliado ou integral possibilita observar a centralidade das organizações no interior da sociedade civil compreendidas como aparelhos privados de hegemonia (APHs). Em outras palavras, identificar as relações sociopolíticas subsidiadas pela concepção de Estado ampliado é tarefa importante para compreender os organismos sociais coletivos articulados na sociedade chilena a fim de garantir suas bases de dominação.

Com vistas aos objetivos mencionados, desenvolvemos os seguintes procedimentos metodológicos: levantamento e análise de documentos; pesquisa bibliográfica e análise de redes sociais. O primeiro diz respeito ao levantamento de documentos pertinentes ao tema e a análise das fontes primárias coligidas (documentos oficiais, institucionais e relatórios) encontradas na página eletrônica da ACE. Evangelista (2012) destaca que documentos oriundos do aparelho de Estado, de organizações multilaterais e de agências e intelectuais expressam não apenas diretrizes para a educação, mas articulam interesses e produzem intervenções sociais. O segundo refere-se às produções científicas sobre as diretrizes de políticas educativas para a América Latina e Caribe. O terceiro procedimento baseia-se na metodologia da análise de redes sociais (ARS). A análise de redes sociais é 
um método desenvolvido para a análise de dados relacionais, aqueles em que o investigador está interessado em analisar os laços, contatos, vínculos, conexões que unem sujeitos ou organizações.

\section{A ación colectiva por la educación como expressão da elite orgânica do capital}

O contexto histórico de organização e protestos da classe trabalhadora expresso nas manifestações de greve, passeatas, durante os governos Sebastián Piñera (2010-2014) e Michelle Bachelet (2014-2018), nos leva a observar o processo de organização de uma fração da burguesia chilena que intervém sobre as políticas públicas de educação. $O$ historiador inglês marxista, Edward Thompson (1987), procura circunscrever um método lógico de investigação que seja adequado aos materiais históricos que estão sempre em movimento; portanto, os procedimentos de análise teriam que dar conta das sucessivas modificações do evento histórico. Thompson (1987) parte de uma investigação empírica para observar uma determinada classe, não como um surgimento determinado, mas presente num processo ativo que articula tanto a ação humana, quanto condicionamentos históricos/sociais, pois as classes fazem-se a si mesmas, tanto quanto são feitas.

Thompson (1987, p. 9) entende classe como "um fenômeno histórico que unifica uma série de acontecimentos díspares e aparentemente desconectados tanto na matériaprima da experiência como na consciência"; assim, ressalta que "a noção de classe traz consigo a noção de relação histórica". Seguindo as considerações de Thompson (1987), não observamos a relação histórica de classe como estática e estrutural; ao contrário, é preciso entendê-la nas interações e contextos reais, uma vez que "a classe acontece quando alguns homens, como resultado de experiências comuns (herdadas ou partilhadas), sentem e articulam a identidade de seus interesses entre si, e contra outros homens cujos interesses diferem (e geralmente se opõem) dos seus" (THOMPSON, 1987, p. 10).

Agregando as análises de Bianchi (2007) sobre as formas de associação do capital, consideramos que não são o resultado de uma tendência espontânea à identificação de interesses comuns, mas o produto dessas relações de forças sociais que motivariam a 
junção de interesses antes dispersos e, até mesmo, conflitantes, bem como da capacidade de liderança de certos intelectuais orgânicos. O reconhecimento da importância da ação coletiva burguesa sob a forma da Acción Colectiva por la Educación surge no ano de 2017, circunscrito num cenário de reinvindicações da classe trabalhadora expressas nas manifestações sociais.

Sem ter a pretensão de analisá-las profundamente, cumpre destacar o papel da Confederação de Estudantes do Chile (CONFECH) e do Colegio de Profesores nas reivindicações contra a mercantilização do ensino e a privatização da educação. Juntamente com as lutas dos trabalhadores mineiros, as manifestações estudantis aprofundaram uma crise de representação do sistema político chileno, visível no esgotamento dos modos de processamento dos conflitos prevalecentes a partir do retorno à democracia que negavam toda a participação das forças sociais subalternas na política (BARROETA; SANDOVAL, 2014). Diante desse contexto, essas novas formas de associação burguesa ocorrem mediante a aglutinação de aparelhos privados de hegemonia nas reformas educativas chilenas sob a égide dos princípios da globalização.

No plano político-ideológico, podemos considerar que a eclosão de movimentos sociais, tanto estudantis quanto dos trabalhadores, representa reivindicações nas quais o Estado restrito e as organizações sociais de cunho empresarial se organizam na busca de novos elementos de mediação para o conflito entre o capital e o trabalho. Assim, a produção de consenso se firma na forma de associação entre diversos aparelhos privados de hegemonia, colocando-se como atores com ampla capacidade técnica e experiência para participar na implementação de ações políticas educativas.

Nesse sentido, a Acción Colectiva por la Educación surge como uma modalidade organizativa entre diversas organizações da sociedade civil "comprometidas com uma educação de qualidade, equitativa e inclusiva". No entanto, é importante notar que sociedade civil figura neste contexto como o espaço da liberdade, porém do ponto de vista do campo de lutas, sociedade civil representa a disputa pela hegemonia na qual se articulam interesses privados de natureza classista. Fontes (2010) considera que as entidades da sociedade civil - ou aparelhos privados de hegemonia - se enraízam nos interesses materiais das classes dominantes e das dominadas, penetram o Estado por diversas modalidades e atuam como formadoras de sociabilidades, sobretudo reforçando 
os setores hegemônicos, mas também contestando e criando contra-hegemonias. Elas podem ser consideradas a espinha dorsal da sociedade civil; uma vez constituídas em instâncias associativas, apresentam-se sob formas de associatividade voluntária, expressão da unidade nacional ou porta-vozes de uma neutralidade inexistente.

Considerando as colocações precedentes, o conceito de elite orgânica, elaborado por Dreifuss (1986), mostra-se pertinente, pois permite compreender o conjunto de intelectuais orgânicos ${ }^{3}$ vinculados a uma fração da burguesia. Consideramos que a unidade de análise não são as atuações individuais dos sujeitos históricos, mas o vínculo com suas associações. Logo, as associações são vistas como representação de unidades de ação política significativas de conexões e organizações. Dreifuss (1986) considera que a elite orgânica pode ser definida como o conjunto articulado de agentes políticoideológicos especializados no planejamento estratégico e na implementação da ação política de classe. A elite orgânica é a pensadora de uma classe - 'a parcela esclarecida da burguesia' -, funcionando como 'auto-conciência cultural e política' e núcleo de autocrítica da classe dominante (DREIFUSS, 1986, p. 26).

A elite orgânica tem atuação como agente político acima dos interesses econômico-corporativos dessa fração, visando o Estado e não somente os governos ${ }^{4}$. No entanto, como considera Hoelever (2015), não deve ser vista como epifenômeno, no nível político, da estrutura econômica, por aparecer e constituir-se como um agente relativamente autônomo, já que o grau de conexão com os grupos sociais matriciais é dado justamente pela sua qualidade orgânica.

A ACE se apresenta como um esforço coletivo da sociedade civil que tem como objetivo criar uma agenda educativa de longo prazo, trabalhando com o Estado, independente de governo, ao aportar conhecimento e experiência para gerar uma mudança educativa em grande escala. Portanto, a consideramos como um resultado

\footnotetext{
${ }^{3}$ Foge ao escopo desta pesquisa discutir teoricamente a categoria de intelectual orgânico elaborada por Gramsci. No entanto, seguimos a orientação de uma visão mais ampliada de intelectual que, segundo Silveira (2020, p. 6), "permite apreender sua movimentação, seja ele sujeito singular (professor, empresário, cientista, jornalista, padre, técnico industrial, médico, engenheiro, advogado etc.), seja coletivo (partido, sindicato, organizações empresariais e grupos sociais como o Movimento Escola sem Partido, o Movimento pela Base, o Movimento Todos pela Educação, o Movimento Brasil Livre, o Instituto Brasileiro de Coaching, entre outros)."

4 O conceito tem lastro nos arcabouços de Antonio Gramsci, Nicos Poulantzas e Ralph Miliband. Cf. Hoelever, 2015.
} 
concreto e histórico de um tipo de associativismo educacional, configurando-se uma teia de relações negociadas entre 18 organizações da sociedade civil dos grupos dominantes que se unem, a partir de 2017, produzindo um processo de conformação dos interesses do capital para orientar mudanças nas políticas educacionais do Chile. Além do mais, a ACE coloca-se à disposição para colaborar com outras organizações da sociedade civil, autoridades governamentais e parlamentares, empresas e organizações não governamentais para avançar na agenda e ações concretas de uma política educacional que se coadune com os interesses do capital.

Shiroma (2011) observa que uma das estratégias do Banco Mundial é articular redes existentes nacionais, uma vez que sua presença se torna imbricada entre os demais integrantes. Dessa forma, reconhecer a relação entre os sujeitos/redes que operam localmente só é possível quando se conhece os atores ligados à rede analisada. A tabela abaixo agrupa as 18 organizações que compõem a ACE, o nome do diretor executivo e o ano de criação de cada entidade.

Quadro 1 - Acción Colectiva por la Educación (ACE) - Chile, 2017

\begin{tabular}{|l|l|l|}
\hline $\begin{array}{l}\text { Aparelho privado de } \\
\text { hegemonia educacional }\end{array}$ & Direção executiva & Fundação \\
\hline Fundación Educación 2020 & Alejandra Arratia & 2008 \\
\hline $\begin{array}{l}\text { Centro de Investigación Avanzada } \\
\text { en Educación - Universidade do } \\
\text { Chile (CIAE UChile) }\end{array}$ & Beatrice Avalos & 2008 \\
\hline Fundación Chile & Hernán Araneda e Cristina Aziz & 1976 \\
\hline $\begin{array}{l}\text { SUMMA5 } \\
\text { Laboratório de Pesquisa e } \\
\text { Inovação em Educação para a } \\
\text { América Latina e Caribe }\end{array}$ & $\begin{array}{l}\text { Ministério da Educação do } \\
\text { Brasil, Chile e Colômbia }\end{array}$ & 2016 \\
\hline Elige Educar & $\begin{array}{l}\text { Joaquín Walker e Alionka } \\
\text { Miranda }\end{array}$ & 2009 \\
\hline
\end{tabular}

\footnotetext{
5 SUMMA é o primeiro Laboratório de Pesquisa e Inovação em Educação para a América Latina e Caribe. Foi criado em 2016 com o apoio financeiro do Banco Interamericano de Desenvolvimento (BID) e da Fundação Chile, além dos Ministérios da Educação do Brasil, Chile, Colômbia, Equador, México, Peru e Uruguai. Desde 2018, conta com o suporte dos Ministérios da Guatemala, Honduras e Panamá.
} 


\begin{tabular}{|l|l|l|}
\hline Fundación Súmate & Liliana Cortés & 2008 \\
\hline $\begin{array}{l}\text { Fundación Educacional } \\
\text { Vicaría para la Educación }\end{array}$ & Marcela Marzolo & 2006 \\
\hline Fundación Crecer con Todos & $\begin{array}{l}\text { Fabiola Zambra e Marcelo } \\
\text { Neira }\end{array}$ & 2011 \\
\hline Puentes Educativos & Gonzalo Plaza & 2010 \\
\hline Fundación Portas & Rodrigo Tupper & 2010 \\
\hline Fundación Enseña Chile & Tomás Recart & 2007 \\
\hline Tu Clase Tu País & Eugenio Severin & 2008 \\
\hline Ashoka & Valentina Valech & 2012 \\
\hline Fundación Mis Talentos & Isabel Zúñiga & 1980 \\
\hline Corporación Vida Buena & Alejandro Caro Contreras & 2000 \\
\hline Fundación Origen & Mary Anne Müller Pietro & 1991 \\
\hline Movimiento Aula & Maria Ignacia Aybar & 2015 \\
\hline
\end{tabular}

Fonte: Elaboração própria, Acción Colectiva por la Educación, 2019.

O quadro 1 é interessante porque caracteriza as dinâmicas políticas chaves para a educação no Chile. Tais dinâmicas dos processos políticos abrem uma forte discussão sobre o papel do Estado e da sociedade civil no que se refere aos múltiplos institutos, fundações, centros de estudo orientados para o campo da educação. É importante considerar que não pretendemos fazer uma análise mais detalhada sobre cada uma dessas entidades e, sim, apenas, possibilitar a visualização do cenário histórico maior dentro do qual nasceu a ACE. No entanto, cada um desses aparelhos privados de hegemonia atua de forma isolada nos seus campos, porém combinado com as orientações políticas educativas do ACE.

Para melhor compreender o caráter deliberado e planejado da intervenção política da ACE, Dreifuss (1986) considera que a elite orgânica é o "córtex político" - "um órgão capaz de visualizar objetivos estratégicos e táticos em cenários modificáveis" - que tem como característica o posicionamento de um núcleo de vanguarda político-intelectual que 
visa a articulação e coesão pela conquista da hegemonia e a regulação de conflitos intraclasse. Pondera que a atuação conectiva e mediadora do córtex político é a de garantir uma mínima "unidade classista", pois se coloca como interesse coletivo do capital, mas também como representação da consciência nacional. Logo, para a elite orgânica, é importante que um conjunto de frações subalternas permaneça sob seu controle, pois permite a construção de um bloco de poder cuja frente móvel de ação viabilize sua inserção político-ideológica com fins para a conversão de projetos classistas particulares como se fossem demandas de caráter social (DREIFUSS, 1986).

A ACE prioriza quatro dimensões específicas de trabalho: educação inicial, educação inclusiva, práticas pedagógicas e inovação e gestão escolar. A coordenação técnica é responsabilidade da diretora executiva da SUMMA, Patricia Armingol. Assim, temos a seguinte divisão das temáticas e seus coordenadores:

a) educação inicial: Elige Educar, Joaquín Walker

b) equipes de gestão escolar: Fundación Enseña Chile, Tomás Recart

c) educação inclusiva: Fundación Mis Talentos, Isabel Zúñiga

d) práticas pedagógicas e inovação: Fundación Educación 2020, Alejandra Arratia

A divisão das responsabilidades por áreas temáticas determina que cada entidade responda pelas ações pedagógicas junto aos segmentos a que se destinam, mas também para proporem políticas públicas. Essa aliança estratégica expressa a soma das interrelações dentro das quais as frações da burguesia visam alcançar um objetivo comum: garantir para si todas as soluções de controle entrecruzados dos recursos financeiros e coordenação das ações. Portanto, caracteriza as dinâmicas de um processo político chave para a educação no Chile, qual seja, a atuação de APHs decorrentes do desenvolvimento das forças produtivas e da socialização da política pelo controle hegemônico responsável pela elaboração e difusão de suas ideias.

As estratégias de ação incluem: acompanhamento das políticas educacionais que estão tramitando no Congresso; produção de conteúdos com propostas entregues aos parlamentares; apresentação de opiniões e sugestões nas Comissões de Educação e Fazenda do Senado e na Câmara de Deputados, além de se reunirem com autoridades políticas; propostas para a política educacional; elaboração e disseminação de 
documentos para promover novos projetos e/ou melhorar os projetos existentes. Outras ações incluem a elaboração de um trabalho de comunicação e mobilização da sociedade através de massivas campanhas midiáticas e das redes sociais, utilizando plataformas como Facebook, Instagram, Twitter, Youtube e Vimeo, assim como participam com a emissão e divulgação de pareceres para a imprensa. Todas essas ações os colocam na arena política como ‘especialistas' em questões educacionais.

Podemos perceber a tentativa de construção de uma nova pedagogia da hegemonia (NEVES, 2005), amparada pelo discurso de marketing lançado no Manifesto da Acción Coletiva por la Educación (2019) no qual define uma agenda com problemas e propostas comuns para potencializar a educação das crianças e jovens. Ademais, se propõe a trabalhar com os interesses coletivos da sociedade civil a fim de superar intervenções políticas isoladas e alcançar mudanças significativas em grande escala. A busca pelo fortalecimento de suas ações políticas reproduz um tipo de sociabilidade cuja internalização dos valores do capital pelas classes subalternas contribui para a conformação de um novo tipo de homem necessário em cada tempo histórico (MÉSZÁROS, 2004).

Do ponto de vista do capital, como consideram Avila, Titton e Evangelista (2019, p. 52), "controlar a formação humana é uma necessidade para que o capitalismo possa se colocar diuturnamente como horizonte único da humanidade". Por isso, no atual contexto da reestruturação produtiva, enfatiza-se a importância da qualificação técnica para o ingresso no mercado de trabalho. É diante desse cenário que a educação é convocada a desempenhar uma função que atenda os interesses do capital. Montaño (2002) chama a atenção para a promoção de políticas de redução da pobreza da ampla massa de trabalhadores; a criação de parcerias público-privadas, entre outras "ações articuladas" com empresas, bancos e organizações empresariais e da sociedade civil para colaborar nos encaminhamentos das políticas de enfrentamento da "questão social". Podemos observar que, na sociedade do capital,

[...] a educação institucionalizada, especialmente nos últimos 150 anos, serviu no seu todo - ao propósito de não só fornecer os conhecimentos e o pessoal necessário à máquina produtiva em expansão do sistema do capital, como também gerar e transmitir um quadro de valores que 
legitima os interesses dominantes, como se não pudesse haver nenhuma alternativa à gestão da sociedade, seja na forma "internalizada" (isto é, pelos indivíduos devidamente "educados" e aceitos) ou através de uma dominação estrutural e uma subordinação hierárquica e implacavelmente imposta. (MÉSZAROS, 2008, p. 35)

Os aparelhos privados de hegemonia educacionais são importantes mediadores para a formação da juventude para o mundo do trabalho no qual a proposta de empreendedorismo, competitividade, empregabilidade e trabalho voluntário conformam a preparação para o trabalho simples.

A ACE, em abril de 2019, lança o documento Propuestas desde la Sociedad Civil: promoviendo una educación de calidad, más equitativa e inclusiva para o sistema educacional do Chile, financiado pela Fundação Colunga (FUNDACION COLUNGA, 2020) ${ }^{6}$, priorizando as quatro dimensões que necessitariam passar por reformas: educação inicial, educação inclusiva, práticas pedagógicas e inovação, e equipes de gestores.

No ensino inicial, as propostas visam: (1) diminuir o coeficiente técnico e o tamanho do curso, aproximando-se da média dos países desenvolvidos; (2) progredir no reconhecimento do horário não escolar para os educadores de pré-escola; (3) atrair educadores da primeira infância para a sala de aula e (5) fortalecer o treinamento inicial e de serviço dos educadores e técnicos da primeira infância. Na educação inclusiva: (1) criação de um observatório de iniquidade educacional; (2) sistema integrado para a identificação precoce de iniquidades educacionais; (3) sistema de provisão de apoio e monitoramento de estudantes prioritários; (4) flexibilidade curricular para atenção à diversidade e (5) fortalecer a formação profissional de especialistas, professores e gerentes.

\footnotetext{
${ }^{6}$ A Fundación de Beneficencia Colunga, criada no Chile em 2012, é de origem familiar, constituída pela família Cueto Plaza, controladora da companhia multinacional Latam, através da sociedade Costa Verde Aeronáutica S.A. A Fundación Colunga tem por objetivo fortalecer as instituições filantrópicas para o desenvolvimento de projetos inovadores de Organizações da Sociedade Civil (OSC), que contribuem com plataformas de evidência e colaboração para políticas públicas que desenvolvam soluções inovadoras destinadas à superação da vulnerabilidade e pobreza da infância. Os trabalhos realizados pela Colunga estão inseridos em três linhas de ação: Programa de Desenvolvimento Social, Pesquisa e Políticas Públicas, Núcleo de Inovação Social e articulação e desenvolvimento do ecossistema da sociedade civil e da transformação social. Disponível em: https://www.fundacioncolunga.org/.
} 
Nas práticas pedagógicas e na inovação: (1) criação de uma plataforma para práticas educacionais efetivas; (2) criar um observatório nacional de inovações educacionais e (3) escalar sistema de práticas educacionais eficazes. Nas equipes de gestão, propõem-se: (1) melhoria do sistema de competição para contratação de equipes de gestão; (2) sistema de desenvolvimento profissional para equipes de gerenciamento; (3) Projetar e implementar um nível intermediário eficiente (serviço de educação municipal ou local) focado no aprimoramento do papel pedagógico das equipes de gerenciamento e (4) fortalecer os poderes e a autonomia das equipes de gerenciamento para a tomada de decisões.

De acordo com o documento, essas propostas iniciais visam contribuir para a criação de políticas de qualidade com o Governo e a comunidade educativa. A lógica imposta pela ACE (2019) está direcionada para atender dois objetivos: a capacidade de aprender continuadamente e inovar para poder atingir os desafios do século XXI. Vê-se aqui a influência do Relatório Delors (1998), documento elaborado pela Comissão Internacional sobre a Educação para o século XXI, criada pela UNESCO em 1993, vigente como importante documento para compreender as reformas das políticas educacionais. Como consideram Shiroma, Morais e Evangelista (2011), o relatório aponta indícios significativos sobre a compreensão das políticas praticadas durante a expansão da globalização ao promoverem um processo de exclusão social e desemprego.

O Relatório Delors (1998) apresenta o conceito de educação ao longo da vida, ancorado em quatro tipos de aprendizagens: aprender a conhecer, aprender a fazer, aprender a ser e aprender a viver junto, assinalados como prerrogativas de uma educação harmoniosa, democrática, com recuo da pobreza e da exclusão social (SHIROMA et al., 2011). De acordo com Coan e Shiroma (2012), diante da crise estrutural do capital, os jovens são preparados a vender sua força de trabalho no que se refere à prestação de serviços, bolsas de estudo, trabalhos precarizados e temporários. Além de prepará-los para novas habilidades e competências socioemocionais para resolverem seus problemas, saber correr riscos, arcar com as consequências e, acima de tudo, adquirir capacidade empreendedora. Nesse contexto, o empreendedorismo foi transformado em alternativa para os jovens. Os mesmos autores informam que consta como objetivo do Relatório Delors (1998) a proposta de uma política educacional sobre o “aprender a empreender", 
ou seja, atrelar um sentido à educação de alternativa ao desemprego e manter, dessa forma, a produção coletiva de riquezas para preservar a apropriação privada.

Enfim, as propostas da ACE para educação com ênfase no trabalho colaborativo, em práticas socialmente responsáveis, dado o caráter da experiência técnica de seus membros, nos conduz a perceber o movimento de recomposição da hegemonia burguesa no Chile. Trata-se de um conjunto de propostas que visa atuar por dentro do campo da educação na conformação de um tipo de trabalhador para as demandas capitalistas do século XXI. Bianchi (2004) considera que desde os anos de 1980, o associativismo empresarial vem se expandindo na totalidade dos países latino-americanos. Essa forma de organização burguesa se destaca por meio de três tendências: a expansão de organizações formadas para representar interesses setoriais novos; a difusão de centros de estudos e de divulgação da ideologia empresarial, a criação de novas associações empresariais de cúpula e a renovação de entidades existentes.

\section{A tessitura orgânica da acción colectiva por la educación}

A Análise de Redes Sociais (ARS) é uma metodologia muito utilizada em estudos com enfoque relacional. Redes sociais sistematizam um conjunto de relações (edges) estabelecidas entre determinadas unidades (nodes). Conforme Wasserman e Faust (1994), ARS é uma perspectiva analítica que tem como grande vantagem incluir na análise as relações entre as unidades observadas e não apenas seus atributos. O nosso objetivo é apresentar o sociograma construído com o software NetDraw (BORGATTI, 2002), as conexões e as afiliações dos membros, os intelectuais orgânicos que compõem a ACE, as trajetórias entre as esferas pública e privada, instituições universitárias, bem como os vínculos com organismos internacionais. No desenvolvimento da ARS, a rede apresenta a relação de pertencimento (conexões ou edges) de pessoas (diretores executivos) em instituições (pertencentes à trajetória profissional desses indivíduos), o que possibilita identificar as ações articuladas entre sujeitos e entidades.

A análise dos processos políticos pela abordagem de redes implica observar os padrões de relação entre os atores, suas interdependências e a forma como esses padrões e interdependências influenciam o processo político (KLIJN, 1998); assim como 
contribui para evidenciar relações e ordenações não identificadas previamente (MINELLA, 2013). Para Klijn (1998), as redes de políticas públicas são padrões, mais ou menos estáveis, de relações sociais entre atores interdependentes que tomam forma em torno de problemas e/ou programas políticos. A análise de rede apresenta-se como uma metodologia específica para o estudo das relações sociais. Assim como pondera Marques (2000, p. 32), consideramos a análise de rede "como método para a descrição e a análise dos padrões de relação nela presentes”. Segundo Marques (2003, p. 153), a análise de redes sociais permite visualizar a reprodução dos padrões de relação dos indivíduos para tentar compreender sua influência sobre vários fenômenos sociais e políticos. Dessa forma, a metodologia de análise de redes sociais leva à reconstituição analítica dessas redes e a sua influência sobre inúmeros processos.

Figura 1 - Comitê Executivo e líderes temáticos da Acción Colectiva - Chile, 2019

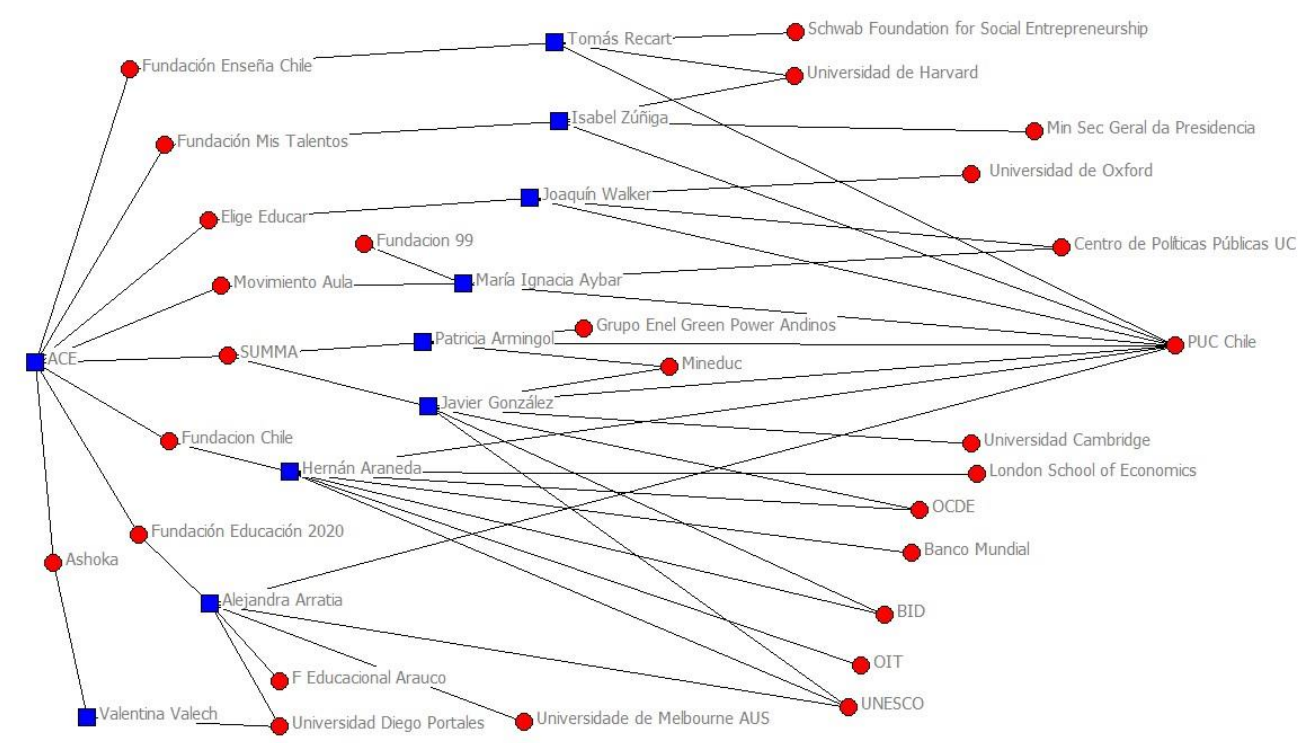

Fonte: Elaboração própria com uso do software Ucinet/ NetDraw (ACCIÓN COLECTIVA, 2017).

Entendemos a rede (Figura 1) como uma representação de uma determinada realidade. Na nossa pesquisa, o potencial da ARS surge pela possibilidade de identificar certas determinações relacionais de uma fração da classe burguesa. A rede analisada representa a composição dos membros da ACE no ano de sua criação, em 2017. Isso tem consequências para o significado das informações, pois conferem três características importantes. Primeiramente, os atores não compartilham espaços simultaneamente na mesma entidade de origem, porém, sua origem de pertencimento advém dos lugares que 
ocupam nos APHs que representam; em segundo lugar, trata-se de analisar a trajetória dos sujeitos históricos como trajetórias que ocorrem dentro das entidades e, terceiro, a presença de instituições internacionais permite que diversos sujeitos passem pelas mesmas instituições, que vão do Aparelho de Estado às empresas privadas.

Procuramos demonstrar as trajetórias profissionais específicas dos diretores executivos da ACE; suas participações plurais nos APHs de origem singular oferecem uma importante reflexão sobre a influência de uma fração da burguesia e, portanto, dos interesses do capital nas políticas públicas educacionais expressadas visualmente nessa malha política. Por isso, a ARS consegue captar o conjunto de conexões entre pessoas e instituições construídas ao longo do período?.

O desafio é, portanto, reconstruir a relação de vínculos e conexões entre sujeitos históricos e os APHs. Assim, como a leitura da esquerda para direita, temos representados nos primeiros círculos vermelhos os APHs de origem; em seguida, os quadrados azuis representam os diretores executivos e os segundos círculos vermelhos demonstram as conexões externas desses sujeitos históricos. Segundo Wasserman e Faust (1994), a análise de redes sociais é baseada na ideia de que as relações entre unidades são importantes. Não é nosso objetivo discutir a escolha de todos os sujeitos e seus APHs de pertencimentos, no entanto, sugerimos observar a centralidade de alguns dos diretores executivos da ACE. A centralidade pode ser vista como uma propriedade dos atores, inseridos em uma determinada rede (WASSERMAN; FAUST, 1994).

É possível compreender a ACE como uma rede caracterizada pela especificidade de poder que reúne uma elite intelectual de função dirigente, pois procura garantir o pleno desenvolvimento do capitalismo por mediação da unidade das burguesias locais em torno do interesse político-econômico. Assim, os vários vínculos podem ser ilustrados graficamente por rede de relacionamentos e de interesses. Os sujeitos têm, na sua grande maioria, mais de um vínculo dentro da rede e com diversas instituições. Por isso, a análise de redes é um instrumento potente para a análise relacional, porque "permite identificar detalhadamente os padrões de relacionamento entre atores de uma

${ }^{7}$ A rede social foi construída com base nas informações recolhidas nos currículos e notícias de jornais. 
determinada situação social, assim como suas mudanças no tempo" (MARQUES, 1999, p. 49).

Podemos perceber que os sujeitos se caracterizam pela passagem por várias instituições; logo, os atributos profissionais, a competência técnica e o capital social adquiridos nas diversas entidades estão fortemente ligados aos interesses de classe. Os diretores executivos tiveram a formação acadêmica na Universidade Católica do Chile na modalidade graduação; em seguida, a formação em pós-graduação em universidades estrangeiras, tanto em stricto sensu como MBA, tais como Harvard (EUA), Oxford (Inglaterra), Cambridge (Inglaterra), London School of Economics (Inglaterra) e Melbourne (Austrália). Entre os diretores executivos, há passagem também por organismos multilaterais como a OCDE, Unesco e a Organização Internacional do Trabalho, assim como por bancos de empréstimos como o Banco Mundial e o BID, além de órgãos do governo, como o Ministério da Educação e o Ministério da Secretaria Geral da Presidência.

No entanto, essas formas de associativismo burguês, desencadeadas pela ação coletiva, são potencializadas de forma significativa pela existência de estruturas de organizações cujo suporte fornece a materialização para compreender novos significados. Esse é o caso das OSCs, sindicatos, partidos políticos, igrejas e associações de natureza diversa que consolidam o processo nas sociedades latino-americanas denominado por Fontes (2010) como conversão mercantil-filantrópica. Nesse contexto, podemos observar a presença de entidades ligadas à igreja católica, tais como Fundación Summate, Vicaría para la Educación Arzobispado de Santiago e Corporación Vida Buena, esta uma agência de publicidade responsável por campanhas sobre a violência infantil.

A presença da Ashoka, organização sem fins lucrativos criada em Washington D.C., nos Estados Unidos, no ano de 1980, pelo estadunidense Bill Drayton, realiza um trabalho de apoio a empreendedores sociais. O objetivo dessa entidade é identificar e investir em líderes empreendedores capazes de desenvolver ideias criativas e inovadoras com a finalidade de provocar mudanças sociais consideradas positivas. A Ashoka seleciona empreendedores que recebem um suporte financeiro que permite a dedicação exclusiva ao projeto social, além de oferecer formação profissional com programas de capacitação, seminários e consultorias. Assim, os empreendedores sociais passam a integrar uma rede 
de alcance mundial por meio de intercâmbios de informações e experiências constituindo uma parceria de disseminação das suas ideias e projetos (ASHOKA; MCKINSEY, 2001).

Observa-se que atuando em rede, esses APHs administram seus próprios negócios por meio de acordos inter organizacionais, além de buscar no Estado investimentos legais e financeiros. Apesar de existir uma heterogeneidade entre os APHs, no que se refere ao ramo educacional, localização estratégica de ação, função, entre outros aspectos, como considera Bianchi (2007), são os diferentes lugares ocupados pelos capitais particulares que nos permitem falar de frações da burguesia. Assim, diferentes frações da burguesia chilena, ao valerem-se da condição de sujeitos históricos da sociedade civil portadoras de interesse na agenda educacional, mobilizam estratégias de ação organizadas a fim de influenciar projetos, discussões e implementações de políticas de acordo com os interesses comuns de classe junto ao Estado.

Todavia, a configuração dessa tessitura permite estabelecer uma unicidade política ao incorporar nas demandas de políticas educacionais junto ao Estado os interesses do capital expressos por organismos internacionais. Os vínculos relacionais, portanto, são estabelecidos pelo pertencimento, simultâneo ou não, a uma mesma entidade e/ou organização. As informações da rede nos permitem visualizar os três sujeitos históricos que possuem centralidade, com maior número de conexão com organismos multilaterais: Alejandra Arratia (Fundación Educación 2020), Hernan Araneda (Fundación Chile) e Jávier Gonzalez (SUMMA).

A rede permite compreender a relação dinâmica entre esses sujeitos que atuam nos APHs e exercem a autoridade pública de orientar as elaborações das políticas educacionais chilenas. Essas relações são determinadas pelos interesses da fração da burguesia que representam, assim como as formas de acesso aos recursos de poder (ser nomeado e influenciar políticas públicas) e também pelas estruturas formais das instituições pelas quais circularam. Com esse mapeamento, é possível observar a relação com organismos da sociedade civil e como estão inseridos na sociedade política.

A apreensão que realizamos ao analisar o sociograma, evidenciado pelas conexões e vínculos que cada diretor executivo estabelece ao longo de sua trajetória individual, é o forte aprofundamento das relações de subalternidade (FONTES, 2010) a uma fração da burguesia chilena. A rede nos permite observar que a burguesia chilena presente nos 
APHs que compõem a ACE é constituída por intelectuais orgânicos de interesse do capital, empresários locais e que mantêm vínculos transnacionais. É possível ressaltar que a presença da fração da burguesia mais internacionalizada e vinculada aos interesses imperialistas atua de modo dependente do capital estrangeiro e, portanto, essa fração hegemônica se perpetua no poder político mesmo que haja troca de governos políticos.

Isso evidencia a ocorrência de sucessivos ajustes entre as frações burguesas para que possam continuar na direção do poder político, uma vez que em se tratando do poder econômico, o Chile é caracterizado pela ideologia neoliberal. É importante destacar o papel, como observa Evangelista (2010), dos intelectuais orgânicos desses APHs, pois estão imbricados numa rede política que segue pela passagem em organizações multilaterais e agências internacionais nas quais articulam interesses, projetam políticas, produzem intervenções sociais, configurando-se como mediadores do interesse do capital.

A atuação conjunta desses aparelhos privados de hegemonia expressos na formação da Acción Colectiva por la Educación se torna essencial para garantir uma unidade classista, no sentido de que permite formar um bloco de poder de ação políticoideológica para o controle das políticas educacionais do Estado. Torna-se, ainda, necessário enfatizar que coincidem com a influência preponderante de diferentes organizações multilaterais quanto à condicionalidade dos empréstimos e das recomendações técnico-científicas para as contrarreformas do Estado chileno. Além disso, a contribuição permanente com a produção e difusão de pensamentos, por meio de assessorias, ocupa uma posição destacada na ação dos empréstimos para os países.

\section{Considerações finais}

O percurso da pesquisa teve como horizonte a educação, entendida como um bem universal, mas que ao longo da vida social do capitalismo conteve implicações relacionadas aos interesses do capital transportando um grau de capilaridade elevado nas políticas educacionais e apreendê-las não se configura como tarefa simples. Nosso objetivo foi o de demonstrar as novas formas de associação da burguesia chilena expressa no surgimento da Acción Colectiva por la Educación, um aparelho de ação política, que surgiu no ano de 2017. 
A compreensão das determinações do surgimento da ACE demonstrou que Aparelhos Privados de Hegemonia são indissociáveis da relação entre sociedade civil e Estado, pois a composição da ACE com a presença das diversas entidades desempenhou um papel importante na defesa dos interesses burgueses no campo educacional no que se refere à preparação, coordenação e implementação das diferentes linhas de ação estratégica. O complexo ACE reúne uma heterogeneidade de APHs que mantêm vínculos de apoio financeiro com organizações estrangeiras dos EUA, constituindo uma rede de caráter transnacional e, ao mesmo tempo, estabelecem uma homogeneidade na ação política.

Da mesma forma, é preciso considerar que essa nova forma de associação burguesa se insere num grau elevado de subalternidade frente às políticas educativas consoantes com o fortalecimento dos vínculos da organização burguesa. Logo, evidenciase a posição, de acordo com Evangelista (2020), do capital educador com um projeto pedagógico classista e burguês, ao levar em consideração o enfrentamento do papel educativo dos APHs. Assim, o poder educativo avassalador do capital surge como expressão de um modo de existência, de uma compreensão de mundo, de determinadas relações de trabalho cuja essência é a exploração do trabalhador pelo capital (EVANGELISTA, 2020).

Por fim, os componentes orgânicos dessa inter-relação entre capital, trabalho e Estado, expressa na associação burguesa ACE, demonstra o assalto à educação na intenção da completa sujeição das políticas educacionais aos interesses do capital em consonância com os princípios defendidos pelos organismos multilaterais. A questão central da dinâmica do processo de produção e reprodução social, constituída no surgimento desse novo tipo de associação burguesa, demonstra que o sistema sociometabólico do capital altera o cenário político chileno com o surgimento do complexo ACE; no entanto, não modifica o controle de uma fração burguesa empresarial na esfera educacional. 


\section{Referências}

ACCIÓN COLECTIVA. Propuestas desde la sociedad civil: promoviendo uma educación de calidad, más equitativa e inclusiva. [Santiago]: Acción Colectiva, 2017. Disponível em: http://www.accioncolectivaeducacion.cl/. Acesso em: 23 mayo 2020.

AVILA, Astrid; TITTON, Mauro; EVANGELISTA, Olinda. Desterro docente e formação humana nos governos petistas. In: Evangelista, Olinda et al. Desventuras dos professores na formação do capital. Campinas: Mercado de Letras, 2019.

\section{BALL, Steffen; YOUDELL, Deborah. Privatización encubierta en la educación pública,} Internacional de la Educación. Londres: Instituto de Educación, Universidad de Londres, 2007. Disponível em:

http://www.joanmayans.com/privatizacion_encubierta_de_la_educacion_publica.pdf. Acesso em: 9 jul. 2020.

BERROETA, Héctor; SANDOVAL, Juan Protestas. Participación y educación pública: discursos sobre lo público en las movilizaciones estudiantiles en Chile. Educar em Revista, [Curitiba], n. 53, p. 19-38, 2014. Disponível em: https://doi.org/10.1590/0104-4060.36578. Acesso em: 27 abr. 2021.

BIANCHI, Álvaro. Empresários e ação coletiva: notas para um enfoque relacional do associativismo. Revista de Sociologia e Política, [Curitiba], n. 28, p. 117-129, jun. 2007. Disponível em: https://revistas.ufpr.br/rsp/article/view/12860. Acesso em: 10 jun. 2020.

BIANCHI, Álvaro. Estado e empresários na América Latina (1980-2000). Antropolítica, Niterói, v. 16, n. 16, p. 101-122, 2004.

BIANCHI, Álvaro. O Ministério dos industriais: a Federação das indústrias do Estado de São Paulo na crise das décadas de 1980 e 1990. 2004. Tese (Doutorado em Ciências Sociais) - Instituto de Ciências Humanas, Universidade Estadual de Campinas, Campinas, 2004b.

BORGATTI, Everett. Ucinet 6 for Windows: software for social network analysis. Harvard, MA: Analytic Technologies, 2002.

CASIMIRO, Flávio Henrique. A nova direita: aparelhos de ação política e ideológica no Brasil contemporâneo. São Paulo: Expressão Popular, 2018.

CENTRO UNIVERSIDAD CATÓLICA POLÍTICAS PÚBLICAS. Las organizaciones de la sociedade civil desde la percepción de los chilenos. [Santiago]: UC, 2015. Disponível em: https://politicaspublicas.uc.cl/publicacion/otras-publicaciones/las-organizaciones-de-lasociedad-civil-desde-la-percepcion-de-los-chilenos-primer-indice-de-valoracion-social-enchile-2016/. Acesso em: 24 mar. 2020.

COMISSÃO ECONÔMICA PARA A AMÉRICA LATINA E O CARIBE (CEPAL) Estudio económico de América Latina y el Caribe: la agenda 2030 para el desarrollo sostenible y 
los desafíos del financiamiento para el desarrollo, [Santiago]: Cepal, 2016. Disponível em: http://repositorio.cepal.org/bitstream/handle/11362/40326/S1600799_es.pdf? sequence=86\&isAllowed=y. Acesso em: 09 ago. 2020 .

COAN, Marival; SHIROMA, Eneida. Educação para o empreendedorismo: forjando um jovem de novo tipo? In: SILVA, Mariléia Maria da; QUARTIARO, Elisa Maria; EVANGELISTA, Olinda. (orgs.). Jovens, trabalho e educação: a conexão subalterna de formação para o capital. Campinas, SP: Mercado de Letras, 2012.

DALE, Robert. Globalização e educação: demonstrando a existência de uma "cultura educacional mundial comum" ou localizando uma "agenda globalmente estruturada para a educação"? Educação e Sociedade, Campinas, v. 25, n. 87, p. 423-460, maio/ago. 2004.

DELORS, Jacques. Educação: um tesouro a descobrir. Relatório para a UNESCO da comissão internacional sobre educação para o século XXI. São Paulo: Cortez, 1998.

DONOSO, Sofia. La reconstrucción de la acción colectiva en el Chile post-transición: el caso del movimiento estudiantil. Buenos Aires: CLACSO, 2014. Disponível em: http://biblioteca.clacso.edu.ar/clacso/becas/20140905014946/Donoso_Informe_Sep_2014. pdf. Acesso em: 25 jun. 2020.

DREIFUSS, René Armand. A internacional capitalista: estratégia e táticas do empresariado transnacional (1918-1986). Rio de Janeiro: Editora Espaço e Tempo, 1986.

EVANGELISTA, Olinda. De protagonistas a obstáculos: aparelhos privados de hegemonia e conformação docente no Brasil. Revista Outubro, [São Paulo], 2020. No prelo.

EVANGELISTA, Olinda. Políticas públicas educacionais contemporâneas, formação docente e impactos na escola. In: ENCONTRO NACIONAL DE DIDÁTICA E PRÁTICAS DE ENSINO, 16., 2012, Campinas. Anais [...]. Campinas: ENDIPE, 2012, p. 39-51.

FIERA, Letícia; FLORES, Renata. A tragédia e a farda: a ascensão das direitas no Brasil contemporâneo. Rev. Práxis e Heg Popular, Marília, v.5, n.6, p. 197-201, jul. 2020. Disponível em: http://revistas.marilia.unesp.br/index.php/PHP/article/view/10610/6623. Acesso em: 14 ago. 20.

FIERA, Letícia. As teias de interesses e influências nas redes de políticas educativas na América Latina e Caribe. Roteiro, [Joaçaba], v. 44, n. 3, p. 1-20, 19 dez. 2019. Disponível em: https://portalperiodicos.unoesc.edu.br/roteiro/article/view/20932. Acesso em: 23 ago. 2020.

FONTES, Virgínia. Formação dos trabalhadores e luta de classes. Revista Trabalho Necessário, [Niterói], v. 14, n. 25, jun. 2018. Disponível em: https://periodicos.uff.br/trabalhonecessario/article/view/9618/6739. Acesso em: 20 sep. 2020. 
FONTES, Virgínia. O Brasil e o capital-imperialismo: teoria e história. Rio de Janeiro: Editora UFRJ, 2010.

FUNDACION COLUNGA Memoria Anual Colunga. [Santiago], 2020. Disponível em: https://www.fundacioncolunga.org/wp-content/uploads/2021/06/Memoria-Colunga-20192020.pdf. Acesso em 9 jul. 21.

GRANEMANN, Sara. Políticas sociais e financeirização dos direitos do trabalho. Em Pauta, Rio de Janeiro, n. 20, p. 57-68, 2007.

HOEVELER, Rejane. O conceito de elite orgânica transnacional em René Dreifuss e o caso da Comissão Trilateral. In: MARX E O MARXISMO 2015: insurreições, passado e presente, 2015, Niterói-RJ. Anais [...]. Niterói: UFF, 2015. Disponível em:

https://www.historia.uff.br/stricto/td/1919.pdf. Acesso em: 13 ago. 2020.

KLIJN, Erick Hans. Redes de políticas públicas: una visión general. Revista redes, [S.I.], 1998. Disponível em: http://revista-redes.rediris.es/webredes/textos/Complex.pdf. Acesso em: 15 jul. 2019.

MARQUES, Eduardo. Redes sociais e instituições na construção do Estado e da sua permeabilidade. Revista Brasileira de Ciências Sociais, [São Paulo], v. 14, n. 41, p. 45-67, out. 1999.

MARTINS, Erika. Empresariamento da educação básica na América Latina: redes empresariais em prol educação. 2019. Tese (Doutorado em Educação) - Universidade Estadual de Campinas, Campinas, 2019. Disponível em: http://repositorio.unicamp.br/bitstream/REPOSIP/335551/1/Martins_ErikaMoreira_D.pdf. Acesso em: 12 mar. 2020.

McGANN, James. Global go to think tank index report: the think tanks and civil society program. Pensilvânia: Universidade de Pensilvânia, 2007. Disponível em: https://www.gotothinktank.com. Acesso em: 11 abr. 2020.

MCKINSEY AND COMPANY. How the world's best-performing schools come out on top. [New York]: McKinsey, 2007. Disponível em: https://www.mckinsey.com/industries/publicand-social-sector/our-insights/how-the-worlds-best-performing-school-systems-come-outon-top. Acesso em: 6 ago. 2020.

MÉSZÁROS, István. Para além do capital: rumo a uma teoria da transição. São Paulo: Boitempo, 2011.

MÉSZÁROS, István. A educação para além do Capital. São Paulo: Boitempo, 2008.

MINELLA, Ary Cesar. Construindo hegemonia: democracia e livre mercado (atuação do NED e do CIPE na América Latina). Cad. CRH, Salvador, v. 22, n. 55, p. 13-40, apr. 2009. Disponível em: http://www.scielo.br/scielo.php?script=sci_arttext\&pid=S0103$49792009000100002 \&$ lng=en\&nrm=iso. Acesso em: 21 jun. 2020. 
MONTAÑO, Carlos. $O$ canto da sereia: crítica à ideologia e aos projetos do "terceiro setor”. São Paulo: Cortez, 2014.

MONTAÑO, Carlos. Terceiro setor e questão social: crítica ao padrão emergente de intervenção social. São Paulo: Cortez, 2002.

NEVES, Lúcia Maria Wanderley (org.). A nova pedagogia da hegemonia: estratégias do capital para educar o consenso. São Paulo: Xamã, 2005. 311p.

SHIROMA, Eneida Oto; MORAES, Maria Célia Marcondes de; EVANGELISTA, Olinda. Política Educacional. 4.ed. Rio de Janeiro: Lamparina, 2011.

SHIROMA, Eneida Oto. A outra face da inclusão. Revista Teias, [Rio de Janeiro], v. 2, n. 3, p. 12, ago. 2007. Disponível em: https://www.e-

publicacoes.uerj.br/index.php/revistateias/article/view/23869. Acesso em: 2 ago. 2020.

SILVEIRA, Zuleide. O Baile de máscaras: O movimento de intelectuais entre estado supranacional e estado integral. Rev. Práxis e Heg Popular, Marília, v.5, n.6, jul. 2020. Disponível em: http://revistas.marilia.unesp.br/index.php/PHP/article/view/10606/6627. Acesso em: 14 ago. 2020.

THOMPSON Edward Palmer. A lógica histórica. In: A MISÉRIA DA TEORIA OU UM PLANETÁRIO DE ERROS. Rio de Janeiro: Zahar, 1981. p. 47-62.

UNESCO. Declaração mundial sobre educação para todos: satisfação das necessidades básicas de aprendizagem. UNESCO: Jomtien, 1990.

UNESCO. A declaração de Nova Delhi sobre educação para todos. Nova Delhi: Unesco, 1993.

UNESCO. O Marco de ação de Dakar educação para todos: atendendo nossos compromissos coletivos. Dakar: Cúpula Mundial de Educação, 2000.

UNESCO. Educação para todos: o compromisso de Dakar. Dakar: UNESCO, 2000.

UNESCO. Educación para todos en las Américas: marco de acción regional. Santo Domingo: UNESCO, 2000.

UNESCO. Marco da educação 2030: declaração de Incheon. Incheon: UNESCO, 2015.

VIOLIN, Tarso Cabral. A sociedade civil e o estado ampliado, por Antonio Gramsci. Revista Eletrônica do CEJUR, [Curitiba], p. 3-14, dez. 2006. Disponível em:

https://revistas.ufpr.br/cejur/article/view/14846/9966. Acesso em: 10 out. 2020.

WASSERMAN, Stanley; FAUST, Katherine. Social network analysis: methods and applications. Cambridge: Cambridge University, 1994. 
Recebido em: 20/03/2021 Aprovado em: 22/04/2021

Universidade do Estado de Santa Catarina - UDESC Programa de Pós-Graduação em Educação - PPGE Revista Linhas Volume 22 - Número 49 - Ano 2021 revistalinhas@gmail.com 